\title{
Design and Implementation of an Automatic Irrigation System
}

\author{
Alamgir Mahzabin ${ }^{1}$, Chowdhury Alma Taziz ${ }^{2}$, Mullick Homaira Amina ${ }^{3}$, Mollah Gloria ${ }^{4}$, \\ Md. Saniat Rahman Zishan ${ }^{5}$ \\ Department of Electrical and Electronic Engineering, American International University-Bangladesh (AIUB), \\ Dhaka, Bangladesh ${ }^{1,2,3,4}$
}

Asst. Professor, Faculty of Engineering, American International University-Bangladesh (AIUB), Dhaka, Bangladesh ${ }^{5}$

\begin{abstract}
Automation is very important in the advanced world. Automation makes life easier, reduces time for working manually and spontaneous. In an irrigation based country it is very important to have a developed irrigation system. This project deals with the automatic operation of the pump to supply water in the field depending on the soil moisture. The system can be operated using solar energy or even the DC voltage converted from AC. This is done by programming in ATMEGA328.
\end{abstract}

Keywords: Solar Tracking Device, Automatic pump control, Automatic Irrigation System, Simulation.

\section{INTRODUCTION}

Use of proper method of irrigation is significant in the field of agriculture. To fulfil this necessity, we introduce an advanced automatic irrigation system. In this automatic system, we have used sensors, digital circuits, water sources and a control unit. An ATMEGA328 microcontroller is used which plays the part to control the whole process of irrigation. It is programmed to turn on a solenoid when the moisture in the soil falls below a certain level which is detected by a moisture sensor. Our circuit implemented, aims to sense and monitor the irrigation system which in turn makes the entire irrigation process much more efficient, less time consuming and less labour intensive. To achieve our goal of a totally automated farm, we decided to cascade three individual projects and merge them into one. The three projects in action are:

- An automatic solar tracking device.

- Automatic pump controller.

- Automatic farm irrigation system

The rest of the paper is organized as follows: some earlier works are highlighted in section II. In Section III, the architecture of the system is described. The simulation study is given in Section IV and the methodology for achieving goals is described in Section V. The discussions and future scope are defined in Sections VI and VII respectively. Finally concluding remarks are made in Section VIII.

\section{EARLIER RESEARCH IN THE DESIGNING AND IMPLEMENTATION OF AN AUTOMATIC IRRIGATION SYSTEM}

The idea of using the power of the sun for heating and lighting was intuitive. Passive solar energy has been used as a form of light and heat since early mankind.
During 19th century, inventors and entrepreneurs in Europe and the U.S. developed solar energy technologies that formed the basis of modern designs. In 1839, nineteen-year-old Edmund Becquerel, a French experimental physicist, discovered the photovoltaic effect while experimenting with an electrolytic cell made up of two metal electrodes. There was enormous interest in the potential of solar energy over the following decades. It was another matter to develop the commercial use the use of solar energy at a time when fossil fuels were cheap and widely available, and the downsides of their use not understood. The first entrepreneurial endeavours in solar, then, took place in particular locations where using the sun rather than coal made greater sense.

The greatest progress in the use of solar power was in the British protectorate of Egypt, where the American entrepreneur Frank Shuman established a solar business. Shuman was attracted to Egypt both as it had a lot of sun, and because mechanized irrigation was ever increasing as the lands adjacent to the Nile River were arable only with proper irrigation. Shuman leased land in the farming village of Meadi-which was also the administrative centre of Egypt - and prepared to have parts for an experimental plant shipped from Philadelphia to Egypt. To save on costs Shuman decided to build the plant from scratch in Meadi, using local materials instead of building parts in Philadelphia and having them shipped to Egypt. The first commercial scale solar plant was thus successfully launched.

\section{ARCHITECTURE OF THE SYSTEM}

The Automatic Irrigation System is designed in such a way that irrigation can be done automatically using less labour, less time and without wasting water. This is done 
by merging three different projects into an individual one where each of them have got a specific operation in the system.

\section{A. Solar Tracking Device}

Solar panels are fitted on the solar tracker. This device tracks the solar energy following the position of the sun during the day so that maximum amount of sunlight is received by the solar panel with the motion of the sun.

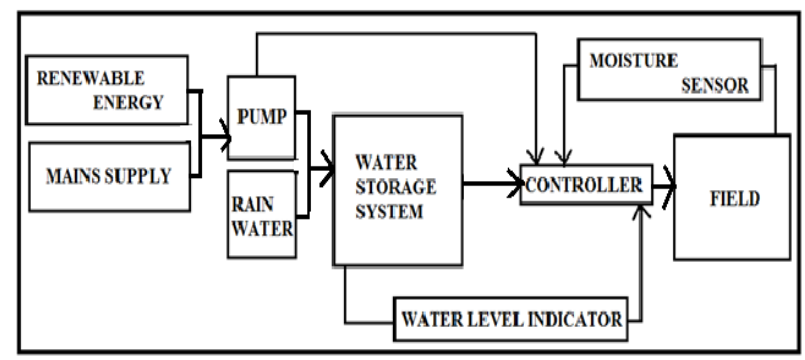

Fig.1. Block diagram of the full system

Using solar panels increased efficiencies can be achieved. It is mostly used in remote areas where there is scarcity of electricity or electrical lines are not situated. The selection of tracker depends on many factors some of which are installation size, electric rates, government incentives, land constraints, latitude, and local weather. The solar tracker reduces the consumption of electricity with greater efficiency. This tracker is accompanied with the LDR variation of resistance and feeds the data to the microcontroller. The microcontroller sends signal to the servo motor. The Bakelite sheet is required to mount the Light dependant resistors (LDRs). The servo motor shifts the position of the solar panels as required sensed by the light dependant resistor (LDR). The LCD display whether solar energy is generated or not. In this way the solar tracking device operates.

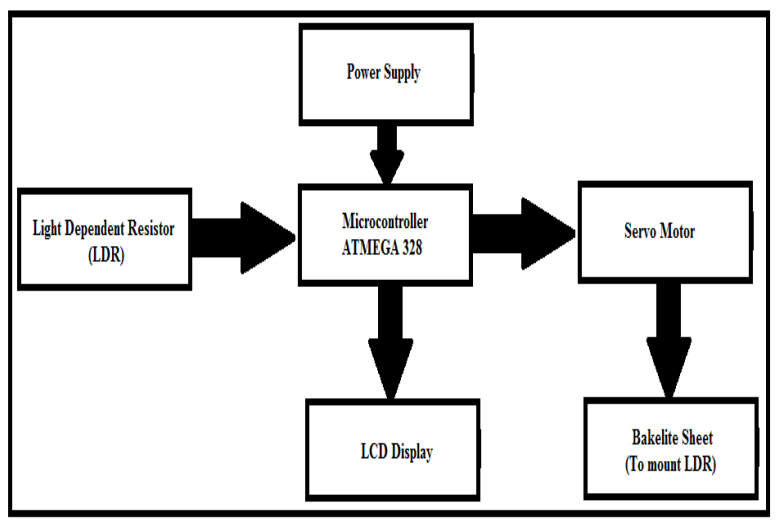

Fig.2. Block Diagram of Solar tracker

The block diagram above depicts the behaviour of the solar tracker. The block diagram shows that the power is supplied to the microcontroller ATMEGA 328. Light dependant resistor (LDR), servo motor and LCD display are connected to the microcontroller. As we see, a light dependent resistor (LDR) senses the position of the sun, through the variation of resistance and feeds the data to the microcontroller. The microcontroller sends signal to the servo motor. The Bakelite sheet is required to mount the Light dependant resistors (LDRs). The servo motor shifts the position of the solar panels as required sensed by the light dependant resistor (LDR). The LCD display whether solar energy is generated or not.

\section{B. Automatic Pump Controller}

Automatic Pump Control system consists of a water storage, water level detector and indicator, relay, solar tracker, dc motor and microcontroller. This automatic pump control can work using two different inputs- solar energy from Solar tracking device and from main power supply. The solar tracker will take the solar energy as an input to the relay that switches it on, switching the pump on to supply the water to the water storage tank. This can also be done when there is no solar power. During night, the power is taken from a dc motor which gets power from the ac (main) supply. The switching on of the pump depends on the water level of the storage. The water level detector has two different levels set-one of them is maximum or high level and the other is low or minimum level. When it detects that the water is at low or minimum level, it will send a signal to the microcontroller to turn on the pump and supply water to the storage and according to the level of the water in the storage, the LEDs will blink which are connected to the water level indicator. There are three LEDs connected to the water level indicator. When one LED or no LED glows then the second relay is switched on to start the pump so that water starts to fill in the storage and as the water level increases the rest of the LEDs starts to glow. When all the LEDs glow, then the relay stops the pump. When the water level is low the pump is switched on and when the water level is high the pump is switched off.

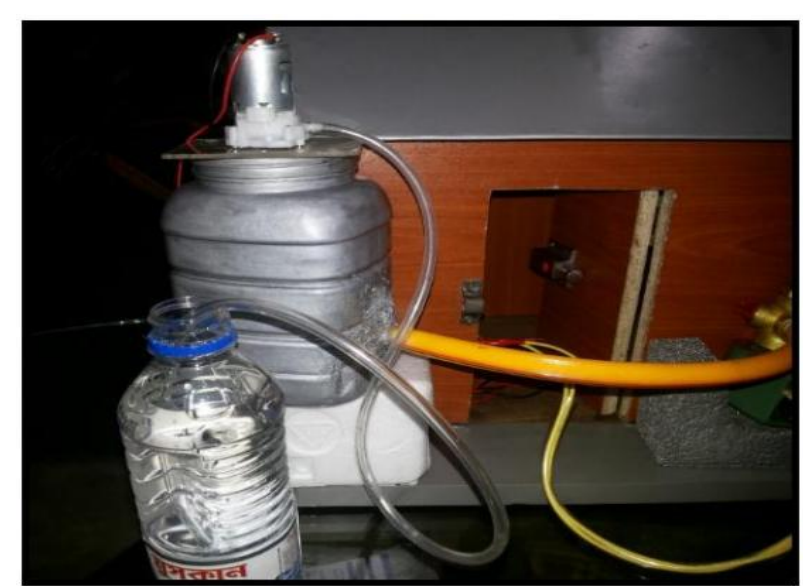

Fig.3. The hardware implementation of the automatic pump control system.

C. Automatic Farm Irrigation system

The automatic irrigation system consists of the soil moisture sensor to sense the soil moisture and feed the input in the microcontroller, the solenoid valve to allow the water supply to the field depending on the soil moisture 


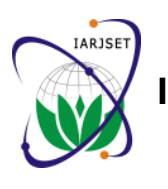

IARJSET

detected, the microcontroller to control all the operations, the LCD display and the power supply as shown in the block diagram below.

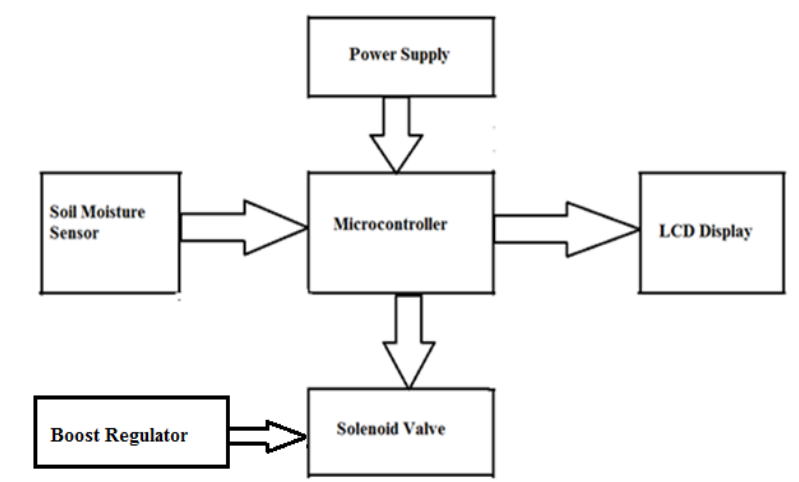

Fig.4. Block diagram for the automatic irrigation system

The Block diagram of an automatic irrigation system using moisture sensor is showed above. It consists of an Arduino with ATmega328 Microcontroller, Moisture sensor, solenoid valve, power supply and LCD Display. At first, the moisture sensor senses the amount of moisture content in the soil and inputs it to the microcontroller. Depending on the moisture content of the soil, it will input the microcontroller to turn on or turn off the solenoid valve which actually gives a pressure to turn on the pump and supply water to the fields. The Moisture level is displayed in the LCD display.

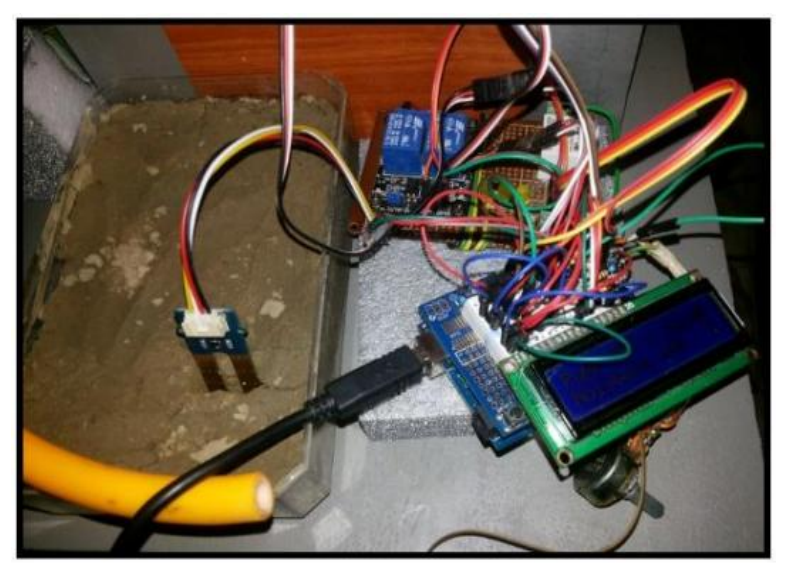

Fig.5 Hardware implementation of the automatic irrigation system

\section{SIMULATION}

The figure 6 shows the full simulation of our project. The simulation is done using Proteus version 7.8. The simulation shows the full experimental setup. The project consists of three parts- Solar tracking device, automatic pump control and Automatic Irrigation system using Moisture sensor. The Solar tracker captures the energy from the sun and use it to convert it generate electricity. This electricity is used to drive the automatic pump control system. The Automatic pump control consists of two relays connected in series and a dc motor. The automatic pump control system can be turned on in two different ways- using the main supply and using the solar energy. When the solar power is available then controller uses the solar power. When it is unavailable then the controller uses the dc power which is converted from ac supply. The solar power is in one input of the first relay and the dc power is connected in the other input. The output of the first relay is connected as the input of the second relay. The output of water level detector and indicator also works as an input to the microcontroller. The water level indicator indicates by lighting LEDs, that is there are three LEDs attached with the Indicator. Microcontroller sends the signal to the dc motor accordingly to switch on or off the pump in the water tank. The soil moisture sensor senses the soil moisture and informs the microcontroller to open the solenoid valve which basically is used to give force to turn on the pump.

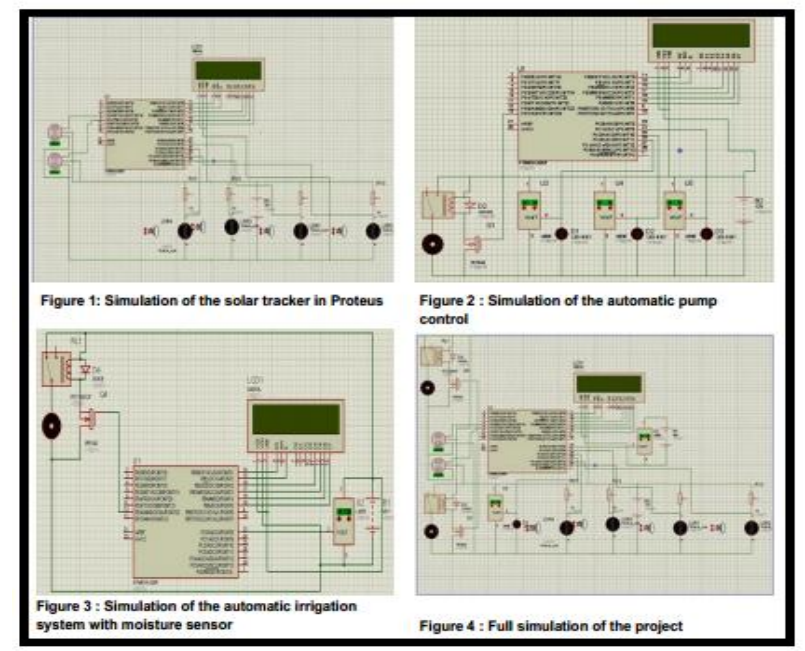

Fig.6. Full simulation process

\section{METHODOLOGY FOR ACHIEVING GOAL}

Step 1: Initially a proposal to design and implement an automatic irrigation system was submitted.

Step 2: The project was designed using the microcontroller ATMEGA328. A storage tank connected to it was used to store water that can be drawn whenever the moisture level in the soil drops. It also consisted of three LEDs which worked as indicators to indicate the level of water stored in the storage. Whenever the water would reach a low level in the storage, it would instruct the microcontroller to turn on the pump to draw water until it reaches a high level and all three LEDs glow.

Step 3: Later, the project was developed and made more specific by cascading three different parts to it-

- A Solar tracker system

- An Automatic Pump controller

- An Automatic Irrigation system

Step 4: The Solar Tracker captures energy from sun and converts it into electricity which will turn the automatic pump control system on especially during the day.

Step 5: The Automatic Pump controller will ensure that there is always water in the storage and it consists of an indicator and a detector. 
Vol. 3, Issue 10, October 2016

Step 6: In the Automatic Irrigation System, input is taken from the moisture sensor as to whether the soil moisture is less than the predefined standard. This information is fed to the microcontroller which decides whether to turn on the solenoid or not to water the field depending on whether the moisture level in the soil is below the required level. The moisture level is displayed in the LCD display.

Step 7: The main goals of this project were to ensure proper communication between every part, minimize the cost of the whole system, and to make the whole system user friendly. This project is developed for users to control the amount of water to a plant. If used commercially, this project is beneficial to individuals as well to the economy as a whole.

\section{DISCUSSION}

In this project we merged three different parts and tried to make a better, environment and user friendly automated farm irrigation system at a very cheap price. The three different parts provide three different benefits to the farmers which are discussed below:

- During summer, our country faces severe power failures. The solar tracker can then easily produce enough electricity to run the pump even if there is a power failure. This is advantageous to both the farmers as well as to the government. This is because, if the demand for electricity decreases at a peak hour, load shedding would reduce which would ultimately help the nation as well as the economy.

- The automatic pump controller helps maintain a standard amount of water in the storage system all throughout the day so that there would be sufficient water to water the farm whenever moisture level falls below the desired level. The controller also ensures that no water is wasted due to overflow of the tank.

- The automatic irrigation system helps to maintain a standard optimum level of water into the soil in order for crops to grow properly thus decreasing the chances of under or over water levels which might ruin the crops.

\section{FUTURE SCOPE}

Since Bangladesh is an irrigation based country, there is a huge scope to work further in this field. Some suggestions for future works are provided below:

- GSM based mobile starter controller: Farmers have to walk miles daily to operate their irrigation pumps. Rampant power cuts with no fixed time slots further add to their plight. After reaching the field, they find out that power supply is not available. A Mobile Starter Controller can help farmers solve this challenge. The device helps them check availability of power supply and switch pumps ON/OFF remotely via a missed call.

- Introducing voice control: Most of the farmers in Bangladesh are illiterate. Handling such sophisticated equipment might be a challenge for them. Thus, if the system could be upgraded by using voice recognition, it would serve as better equipment for them. This would also require further lesser labours to work in field.

- Wind power to produce electricity: The sun is not always available during the day or even all year round in some countries. Wind power could be an alternative source to produce electricity. Thus, even at night, when the sun is not available, electricity can be generated and used.

\section{CONCLUSION}

Our paper provided the design processes to build a large system consisting of several individual parts with several functions. For hardware implementation, proper organizations had to be made to make the parts to communicate with each other smoothly with very minimum error. Analysis has been shown and on the basis of the analysis, proper decisions were made that required for completely implementing the automatic irrigation system. The whole system together exhibits numerous features which can be used in several ways according to need and thus our designed and implemented automatic irrigation system is quite user friendly too.

\section{ACKNOWLEDGEMENT}

This research would have been impossible without the valuable contributions and limitless help of several individuals. First our gratitude goes to Almighty that our research was done on time and also we would like to thank our parents for their continuous blessings and support. We have truly drawn upon our own experience as students of Engineering \& we have also received help from number of persons while doing the research work and writing the paper. Foremost, we would like to express our sincere gratitude to Mr. Kazi Ahmed Asif Fuad, Lecturer, Faculty of Engineering, AIUB and Mr. Toriqul Islam Bhuiyan for their comments, inspiration and support.

\section{REFERENCES}

[1] Automatic Irrigation Based on Soil Moisture for Vegetable Crops [Online] (Accessed on 10.9.2013) Available: http://edis.ifas.ufl.edu/pdffiles/ae/ae35400.pdf

[2] Automatic Irrigation systems [Online] (Accessed on 6.8.2013) Available: http://www.chilliwacktimes.com/news/automaticirrigation-systems-1.431180

[3] Sun power signature black solar panels [Online] (Accessed on 8.10.2013) Available: http://us.sunpowercorp.com/homes/productsservices/solar-panels/signature-black/

[4] The advantages of water level controller [Online] (Accessed on 14.10.2013) Available: http://www.ehow.com/info_8688159_adv antages-water-level-controller.html

[5] Case Study 4, $09 \mid 2012$ Solar powered Vineyard Irrigation system [Online] (Accessed on 8.10.2013) Available: http://www.lorentz .de/pdf/lorentz_casestudy_vineyardlurton_chile_en-en.pdf

[6] VH400 Soil moisture sensor probes [Online] (Accessed on 12.11.2013) Available: http://www.vegetronix.com/Products/VG40 0/ 